\title{
Detection of iceberg using Delay Doppler and interferometric Cryosat-2 altimeter data
}

\author{
Tournadre Jean ${ }^{1,}{ }^{*}$, Bouhier Nicolas ${ }^{4}$, Boy F. ${ }^{2}$, Dinardo S. ${ }^{3}$ \\ ${ }^{1}$ Laboratoire d'Océanographie Physique et Spatiale, IFREMER, CNRS, Université de Bretagne \\ Occidentale, Plouzané, France \\ ${ }^{2}$ Centre National d'Etudes Spatiale, Toulouse, France \\ ${ }^{3}$ HeSpace/EUMETSAT, Darmstad, Germany \\ ${ }^{4}$ FRANCE \\ *Corresponding author : Jean Tournadre, email address : jean.tournadre@ifremer.fr
}

\begin{abstract}
:
The Cryosat-2 Synthetic Aperture Interferometric Radar Altimeter (SIRAL) altimeter is the first altimeter that can operate in three different modes over the ocean: the classical pulse limited LRM, the Delay Doppler or SAR and the SAR Interferometric modes. It offers a unique opportunity to test, validate and compare the capabilities of the three modes for the detection and analysis of small icebergs $(<3 \mathrm{~km}$ in length) already demonstrated for classical altimeters. Over most of the sea-ice free ocean, SIRAL operates in LRM mode and the classical iceberg detection algorithm can be applied without modification. It can also be applied to the Reduced SAR or pseudo-LRM data computed from SAR and SARin data. In SAR mode, iceberg signatures are bright spots in the waveform thermal noise part. They can be easily detected using classical image processing tools. The area of the iceberg is estimated using the size of the signature. In SARin mode, the coherence of the signals can insure the presence of scatterers above the sea surface and is used with the SAR detection algorithm to reduce the probability of false alarm and to better delineate icebergs. Interferometry allows for the first time to map the iceberg and the iceberg free-board at an unprecedented resolution opening a new way of investigation of the distributions of size, free-board and volume of the small icebergs that are responsible of large fraction of the freshwater flux into the ocean.
\end{abstract}

\section{Highlights}

- Detection of small icebergs using Cryosat-2 altimeter 3 modes (LRM, SAR, SARin) - Estimation of iceberg's area from the three modes - First method of estimation of iceberg freeboard from Interferometric altimeter data

Keywords : Small iceberg detection using Cryosat-2 three modes of operation, Estimation of iceberg's area, Estimation of iceberg's free-board from Interferometric altimeter data 


\section{1. Introduction}

2 Icebergs are an important part of the climate system as they interact 3 with the ocean, atmosphere and cryosphere (Hemming, 2004; Smith, 2011).

4 They represent up to half of the mass loss of Antarctic ice sheet (Rignot 5 et al., 2013; Depoorter et al., 2013) and play an important role in the global 6 freshwater cycle by delivering freshwater to regions far from the ice sheet 7 margins (Tournadre et al., 2016; Gladstone et al., 2001; Silva et al., 2006). In 8 the northern hemisphere, ice discharge from the Greenland Ice sheet increased 9 between 2000 and 2012 while its relative contribution to the total volume loss 10 declined from 58\% before 2005 to $32 \%$ between 2009 and 2012 (Enderlin et al., 11 2014). The iceberg cold melt-water affects the upper ocean by freshening and cooling due to their uptake of latent heat. Several studies have revealed that freshening and cooling have opposing effects on ocean stratification, as cooling enhances the surface density, promoting deep mixing, whereas freshening decreases the water density, stabilizing the water column (Jongma et al., 2009; Green et al., 2011). Numerical models of the Southern Ocean 
circulation are now routinely interactively coupled with a thermodynamic iceberg model (Jongma et al., 2009; Merino et al., 2016).

In the Southern Ocean, large icebergs $\left(>400 \mathrm{~km}^{2}\right)$ transport over $70 \%$ of the volume of ice but their melting only represents $20 \%$ of the total mass loss (Tournadre et al., 2016). Small icebergs $\left(<10 \mathrm{~km}^{2}\right)$, although they constitute only $3-5 \%$ of the total ice volume, represent the major part of the freshwater flux into the ocean (Tournadre et al., 2016). While large icebergs transport ice over long periods and large distances they constantly generate smaller icebergs through fragmentation, the latter acts as a diffusive process and are the main component of the freshwater flux (Tournadre et al., 2016).

Tournadre et al. (2008) demonstrated that icebergs between 0.01 and $9 \mathrm{~km}^{2}$ (0.1 to $3 \mathrm{~km}$ in length for square icebergs), referred as small icebergs thereafter, at least in open water, have a detectable signature in the thermal noise part (TNP) (i.e. above the sea surface) of high resolution (HR) waveforms of pulse-limited altimeters that can be easily detected. Under hypotheses of constant ice backscatter and iceberg free-board, the iceberg's area can be inferred from the measured backscatter and range (Tournadre et al., 2012). A twenty-two year (1992-2014) Southern Ocean climatology of the probability of presence, volume of ice and surface based on the analysis of the archives of nine conventional altimeters has been produced within the french Centre National d'Etudes Spatiales founded ALTIBERG project (Tournadre et al., 2016). Synthetic Aperture Radar (SAR) imagers are also powerful instruments to detect, analyze and characterize iceberg. Several iceberg detection algorithms have been published based on single channel data (Gill, 2001; Gladstone and Bigg, 2002; Silva and Bigg, 2005; Wesche and 
Dierking, 2012; Mazur et al., 2017a) or more recently on fully-polarimetric SAR data (Denbina and Collins, 2014; Marino et al., 2016). SAR imagers are well designed to study the spatial distribution of icebergs, but, mainly because of the irregular and poor coverage of some regions (such as the South Atlantic), it is not yet possible to build a small iceberg climatology using SAR data. Furthermore, the amount of data to process and the computing time required by the SAR detection algorithms, even with the increase of computer processing capabilities, still limit their operational use. On another hand, the limited swath of altimeters while limiting their capability to estimate an instantaneous spatial distribution, allows to obtain independent randoms samples of the iceberg population. This, combined with their regular temporal sampling patterns, allows a good estimate of the statistical characteristics of the iceberg ensemble(probability of presence, area).

Since the launch of Cryosat-2 in 2010, a new generation of altimeters using Doppler and interferometric capabilities has emerged and will most probably become the standard for the upcoming altimeters, at least the Doppler one as it is already the case for the Sentinel-3 altimeter launched in 2016 (Wingham et al., 2006). The Delay-Doppler Altimeter (DDA) concept (also known as SAR altimetry) was first proposed by Raney (1998). Delay-Doppler altimeters have high pulse repetition frequency $(\mathrm{PRF})$ to ensure pulse-to-pulse coherence, leading to a potential along-track resolution around 300 meters, improved signal-to-noise ratio and enhanced altimeter ranging performance. The Cryosat-2 Synthetic Aperture Interferometric Radar Altimeter (SIRAL) uses the SAR mode over ocean areas where sea ice is prevalent as well as over some test areas (ESA-ESTEC, 2007). 
The SAR interferometric mode (SARin) is CryoSat's most advanced mode, primary used around the ice sheet margins and over mountain glaciers. Here, the altimeter performs synthetic aperture processing and uses a second antenna as an interferometer to determine the across-track angle to the earliest radar returns. The SARin mode provides thus the exact surface location being measured when the surface is sloping and can be used to study more contrasted terrains, like the margins of the Antarctic continent or Greenland. Over most of the sea-ice free ocean, SIRAL operates in the standard Low Rate Mode (LRM) that is the conventional pulse-limited radar altimeter mode.In this mode the data rate is much lower than for the other measurement modes. The SIRAL data offer a very good opportunity to test the capabilities and merits of three different altimeter operating modes for the detection and estimation of small icebergs characteristics (free-board and surface). The algorithms that will be developed will then be used in the near future to process the whole archive of Cryosat-2 and Sentinel-3 to increase the existing ALTIBERG database. They will also be used to improve our knowledge of the geographical distribution of small icebergs (especially in the Northern Hemisphere), their distribution of size and the volume of ice they transport. Finally, they will be included in the operational processing chains of future SAR and SARin altimeters.

The data, detection method and quantification of iceberg characteristics for the three operating modes are presented in Section 2. For SAR and SARin modes, a case study comparing the results of the altimeter data analysis to cloud free satellite visible or SAR images is presented. It is always quite difficult to find clear visible images coincident with altimeter passes and 
SAR images were, until the launch of Sentinel-1A which provides a much better coverage of high latitude regions, quite scarce. The two best cases we found are located near Greenland and demonstrate thus that the detection is also possible in the Northern Hemisphere where icebergs are generally smaller than Southern Ocean ones. The SAR and SARin mode are also compared to the Reduced SAR mode, i.e. to pseudo-LRM (pulse limited like) data computed from SAR or SARin data through a process known as SAR reduction (Boy et al., 2016; Gommenginger et al., 2013). Indeed, in order to build long time series of iceberg statistics it is essential to have a base of inter-comparison and inter-calibration between pulse limited altimeters and SAR-SARin ones.

\section{CRYOSAT-2 SIRAL data and Method of detection}

CryoSat-2 orbits on a non-sun-synchronous polar orbit (92 inclination) at an altitude of $713 \mathrm{~km}$. A detailed description of the mission and altimeter is given by Wingham et al. (2006) and an overview of the products in ESAESTEC (2007). The default SIRAL operating modes, LRM, SAR, SARin or no measurement, are determined using a geographical mask defined by the satellite mission control center. The mean coverage of the different modes is given in Figure 1.

\subsection{LRM detection}

In LRM mode, SIRAL operates in the classical pulse limited mode. The Tournadre et al. (2008) method of iceberg detection that has already been applied to eight altimeters by Tournadre et al. (2016) to create the ALTIBERG small icebergs database can be applied without modification to the 
Cryosat-LRM data. Basically, any target emerging from the sea surface gives an echo in the TNP of altimeter waveforms if its range lies within the altimeter analysis window and if its backscatter is higher than the noise level. The range depends on the distance from nadir and on the target elevation. The target signature in the waveform space is a parabola whose characteristics depend only on the orbit parameters. The method of detection is presented in detail by Tournadre et al. (2008) and is summarized in Appendix. The Cryosat-2 LRM archive has already been processed and is included within the ALTIBERG data set (Tournadre et al., 2016). Figure 2 presents all the icebergs detected in the Southern Ocean from 2010 to 2016 as well as an example of detected iceberg signatures. The iceberg area is estimated from the iceberg backscatter and range using a backscatter model (Tournadre et al., $2012,2016)$

While it is not possible to transform LRM mode to SAR mode data, it is possible to generate pseudo-LRM data from SAR or SARin data through a process known as SAR reduction or RDSAR. Several methods have been proposed to produce pseudo-LRM (RDSAR) by Boy et al. (2016) or Gommenginger et al. (2013). It is beyond the scope of this paper to analyze the different RDSAR methods that give very similar results for the waveform TNP where iceberg signatures can be detected. The LRM detection algorithm can also be applied to RDSAR data without modifications. An example of iceberg signature in RDSAR data is given in Figure 4-a and -b.

\subsection{Delay Doppler or SAR Mode}

The SAR mode is used over ocean areas where sea ice is prevalent and over some test areas. In this mode, the altimeter transmits bursts with a 
frequency of about $85 \mathrm{~Hz}$ (Wingham et al., 2006). Each burst contains 64 coherent pulses (transmitted at a 18,182 Hz PRF) which are measured over time windows of 128 bin length $(60 \mathrm{~m})$ and are then processed by alongtrack FFT to obtain the Delay Doppler map (DDM) of the surface-reflected signal. Sixty-four Doppler beams of equal angular sectors are thus obtained. Each Doppler beam is about $250 \mathrm{~m}$ wide in the along-track direction and the interval between bursts corresponds to the satellite moving forward by $80 \mathrm{~m}$ each time in SAR mode (290 $\mathrm{m}$ in SARin mode). The strips laid down by successive bursts can be "stacked" to obtain multiple looks of the same portion of the surface. After range alignment including slant, tracker and Doppler range corrections and after range compression (Dinardo, 2013; Ray et al., 2015; Boy et al., 2016), stacks of co-located Doppler beams (L1B-S data) are produced. The incoherent summation of the L1b-S finally gives the SAR Echo (or waveform). In this study, we used the DDM from the ESA Level-1A (FBR) data and the SAR waveforms from the ESA Level-1B data. The L1B-Ss were obtained using the ESA Grid Processing On-Demand (GPOD) and SARvatore (SAR versatile altimetric tool-kit for ocean research and exploitation) (Dinardo, 2013) that allows to reprocess Level-1A data using the user's own configuration parameters.

Figure 4 presents an example of iceberg detection using SAR mode data near Greenland (see Figure 3). Two icebergs are clearly visible on the MODIS image taken 5 hours before the Cryosat pass 2889 cycle 9, on 07/10/2015. The iceberg signatures are clearly visible in the RDSAR waveforms near $74.9^{\circ}$ $\mathrm{N}$ and $75.0^{\circ} \mathrm{N}$ in the form of characteristic parabolas similar to the ones presented in Figure 2. The waveforms have been re-positioned using the L1 
window delay provided by the initial height or a coarse height and fine height (Bouzinac, 2012). The detection of the two icebergs using RDSAR data is illustrated in Figure 4-a and b. The convolution of the waveforms and the parabolic filter characteristic of iceberg signature (Figure 4-b) is first used to detect the local maximums of correlation (red isolines) and the waveforms are then used to estimate the position and value of maximum backscatter represented as black circles in Figure 4-a. Two less intense parabolas associated to the iceberg's signatures can also be seen at $74.9^{\circ} \mathrm{N}$ and $75.0^{\circ} \mathrm{N}$. They correspond to echoes from scatterers at different elevations and/or locations within the iceberg. By design the LRM detector detects only the strongest echo.

Figure 4-e and -f present the DDM and L1b-S echoes at $75^{\circ} \mathrm{N}$, i.e where the northernmost iceberg is closest to the ground track. Within the DDM the iceberg's signature reduces to a bright spot within the waveform TNP. Its range depends on the iceberg's free-board and distance from nadir while its Doppler frequency depends of the along-track distance. The stacking and multi-looking process corrects the range within the DDM and co-locates the Doppler beams from different bursts. The iceberg's signature within L1b-S should therefore be a bright line of constant range (Figure 4-d). However, the specularity of ice backscatter and the antenna beam pattern limit the signature to small incidences.

The incoherent summation used to produce the SAR echoes reduces the icebergs LRM/RDSAR parabolic signatures to bright spots (Figure 4-c). This kind of signatures was also observed for ships (Gómez-Enri et al., 2016). Several image processing algorithms exist to detect bright spots. They are 
based on noise reduction, signal enhancement and signal thresholding to create a binary image in which connected components (CC) are detected (see for example Smal et al. (2010)).

Compared to LRM/RDSAR data, the L1B-S incoherent summation also strongly reduces the noise level of the waveforms TNP used for detection. It can be considered as negligible, which facilitates the detection. To enhance the iceberg signatures, the waveforms are normalized by the mean waveform $(\overline{W F})$ and rms $\left(\sigma_{W F}\right)$ computed for each Cryosat cycle,

$$
W F^{\prime}(i, j)=(W F(i, j)-\overline{W F}(j)) / \sigma_{W F}(j)
$$

A binary image is then created by thresholding $W F^{\prime}$ at 4 (i.e. $4 \sigma_{W F}$ ). The image CC's are computed using a classical graph theory algorithm such as the Matlab(c) bwconncomp or SCiPy label routines. The CC's properties; area, position, mean and max backscatter; are then estimated using Matlab(c) or $\mathrm{SCiPy}$ regionprops routines. The icebergs detected using this algorithm are shown as red isolines in Figure 4-c. Table 1 presents the iceberg's characteristics in RDSAR and SAR data. The two main icebergs signatures in RDSAR data are also detected at the same locations in SAR data (number 1 and 4 in Table 1). The iceberg SAR maximum backscatter is significantly smaller than the RDSAR ones (Table 1) because the L1b-S averaging while reducing the noise level also smooths the iceberg signatures because of the high ice specularity compared to water.

The SAR algorithm allows the detection of the secondary signatures of the two icebergs (number 2 and 3 ) as well as the detection of an iceberg (number 5) too small to be detected in the MODIS image and whose backscatter is not high enough to come out of RDSAR noise. The area of the two main 
icebergs is estimated at 1.1 and $0.26 \mathrm{~km}^{2}$ using the RDSAR backscatter and the Tournadre et al. (2016) method. Due to the low resolution of MODIS images $(250 \mathrm{~m})$ and the difficulty of precisely delineate the icebergs only crude area estimates can be made. The image analysis gives $0.6-1 \mathrm{~km}^{2}$ and $0.3-0.4$ $\mathrm{km}^{2}$ for the two icebergs; in good agreement with the RDSAR values. The icebergs area can also be estimated from the size of SAR signature. While the along-track resolution is $300 \mathrm{~m}$, the across-track resolution depends on free-board elevation and distance from nadir (Equation A.1). Icebergs with $28 \mathrm{~m}$ free-boards can only be detected if their distance from nadir ranges from 2 to $7 \mathrm{~km}$ (Tournadre et al., 2016). Between 2 and $7 \mathrm{~km}$, the SAR range bin width, $d y$, varies from $\sim 75$ to $\sim 20 \mathrm{~m}$. Two area estimates are computed, the first one is the sum of the CC's area multiplied by the along track and across-track resolution

$$
a_{i}=\sum_{j} s_{j} d x d y
$$

where $s_{i}$ are the area (in pixels) of the CCs associated to the iceberg, and $d x$ and $d y$ are along and across-track resolutions. The second method assumes that the iceberg's length in range, $l_{y}$, extends from the minimum to the maximum range values of the CC's detected at the same along-track location while the width, $w_{x}$, is the along-track width. The iceberg's area is thus

$$
A_{i}=w_{x} d x l_{y} d y
$$

The minimum and maximum of range bin width, $d y$ are then used to compute minimum and maximum values of the two area estimates. The first 
Table 1: Characteristics of the detected icebergs in Cryosat-2 SAR pass 2889 cycle 9, 2015/10/07 23:36 UT; RCS: radar cross section

\section{SAR}

RDSAR

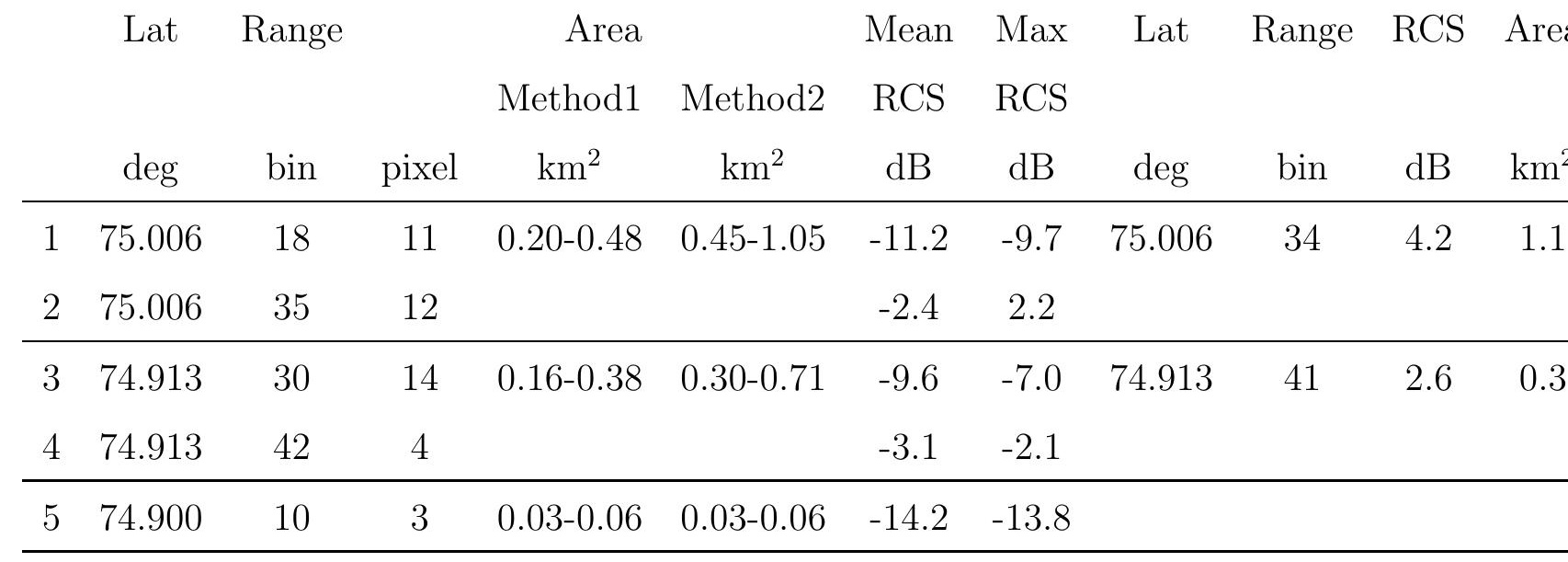

method gives $0.2-0.48$ and $0.16-0.38 \mathrm{~km}^{2}$ for the two icebergs while the second ones gives $0.45-1.05$ and $0.30-0.71 \mathrm{~km}^{2}$ respectively. Compared to the RDSAR and MODIS estimates, the first method appears to largely underestimate the area (by almost a factor 2) while the second method estimates are of the same order of magnitude (see Table 1). The sensitivity of the detection and size estimate on the power threshold is presented in Appendix Appendix B.

The uncertainty on range bin size, as well as the difficulty to precisely estimate the size of the signature lead to a large uncertainty on the SAR area estimate. RDSAR area estimates are certainly more robust. It should be noted that the new Sentinel-3 L1 products provided both RDSAR and SAR echoes and can be used to better analyzed the relationship between backscatter, signature size and icebergs area. For the smaller iceberg detected 
at $74.9^{\circ} \mathrm{N}$, the area can only be estimated using SAR data and both methods give an area of $0.03-0.06 \mathrm{~km}^{2}$.

\subsection{SAR interferometry mode}

The principles of interferometric altimetry were first proposed by Jensen (1999) and lead to the development of the Cryosat mission. A detailed description of the principles and processing of the Cryosat SARin data is given in Wingham et al. (2006). The main (left) antenna transmits the radar signal and the two antennas measure the bacskcattered echo waveform (see Figure 5). The main complex waveform is multiplied with the complex conjugate of the second antenna waveform. The phase of the resulting cross-channel waveform is then defined as the interferometric phase difference, which results from the slight range difference of an off-nadir scatterer for the two antennas. The normalized modulus of the conjugate product gives the estimate of the signal coherence. The stacked SAR echoes for both antennas are computed using the SAR mode processing. The SAR echoes, phase and coherence are provided in ESA Level-1B products. In SARin mode the waveform analysis window is increased to 512 bins $(240 \mathrm{~m})$ to better sample sloping terrains. In the Baseline- $\mathrm{C}$ data products used in this study, the use of zero-padding prior to FFT processing further increase the number of range bins to 1024 without changing the range window. Each bin corresponds thus to $1.565 \mathrm{~ns}$ or $0.23 \mathrm{~m}$ in range.

The interferometric phase difference, $\Delta \psi$, is related to the off-nadir angle, $\alpha$, by

$$
\Delta \Psi=\frac{2 \pi B}{\lambda} \sin (\alpha)
$$


where $\lambda$ is the radar wavelength and $B$ is interferometer baseline (distance between the two antennas). Under the small angle approximation, the offnadir angle $\alpha$ is

$$
\alpha=\frac{\lambda \Delta \Psi}{2 \pi B}
$$

Galin et al. (2013) estimated an angle scaling factor $a\left(\alpha^{\prime}=\alpha / a\right)$ to compensate slight differences between the two SIRAL antennas. The across-track distance to nadir, $d_{0}$, is given

$$
d_{0}=H_{i} \alpha^{\prime}
$$

where $H_{i}$ is the range defined by $H_{i}=c t_{i} / 2, t_{i}$ being the pulse two-way travel time.

Taking the earth's curvature into account, an iceberg detected in range bin $b_{1}$, corresponding to travel time $t_{1}$, and at off-nadir $\alpha_{1}$, has a free-board given by (Nanda, 2015)

$$
\delta=\left(H-H_{i} \cos \alpha_{1}+R_{E}(1-\cos \beta)\right) \cos \beta
$$

where $\beta=H / R_{E} \alpha_{1}$ and $H_{i}=c t_{1} / 2$. The SARin echoes are similar to the SAR ones, except that the number of range bins in the echoes TNP is significantly larger ( $125 \times 2$ vs 50$)$. The swath over which icebergs can be detected which is of the order of $6 \mathrm{~km}$ is thus significantly increased to 12 $\mathrm{km}$. The SAR detection algorithm can be applied to the SARin waveforms without modification. However, in the echoes TNP the signals received by the two antennas are by nature random noise and thus incoherent.

The estimated phase difference is thus a random noise while the coherence should be 0 . If a target emerges from the sea surface, the signals received by 
the antennas becomes coherent. High coherence values indicate the presence of scatterers and are used to further improve the detection and decrease the probability of false alarm. Only samples with coherence larger than 0.6 are considered to construct the binary image used for detection. The sensitivity of the method to the coherence threshold is presented in Appendix Appendix B.

Figure 6 presents an example of iceberg detection in SARin mode (Cycle 9 Pass 2772, 07/02/2015 22:10UT) near Greenland (see fig. 3). The waveforms, coherence and phase difference have been re-positioned using the L1 window delay and large and fine altitude instructions. The phase difference is corrected for the pre-launch interferometric baseline of 0.612 radians (Bouzinac, 2012). Several icebergs are clearly visible in the MODIS image taken less than 45 min after the Cryosat pass (07/02/2015 20:10 UT). The signatures of 5 icebergs are clearly visible in the SARin waveforms between $64.1^{\circ} \mathrm{N}$ and $61.2^{\circ} \mathrm{N}$ (Figure 6-a) and twenty-one CC's are detected. The coherence presented in Figure 6-b confirms that icebergs are associated to very high coherence (between 0.71 and 0.99). The phase difference within CC's (Figure 6-c) strongly differs from the surrounding white noise and presents a high homogeneity. The $\mathrm{CC}$ characteristics as well as the iceberg area estimated using Equation 3 are presented in Table 2. As in the SAR example, the icebergs are associated to several (3 to 7) CC's corresponding to different elevations and/or portions of the icebergs. The across-track distance from nadir and free-board, computed using Equations 6 and 7 for each CC, are presented in Figure 6-d and -e. It should be noted that phase unwrapping is not necessary because the range of iceberg free-board $(<100 \mathrm{~m})$ is small 
enough to be fully covered by one phase rotation $[-\pi+\pi]$.

As for SAR mode, RDSAR waveforms can also be computed from SARin data. The RDSAR analysis (see Supplementary Information figure S1) detects only 2 icebergs (number 1 and 2) whose characteristics are given in Table 2. Iceberg 3 has a parabolic signature that overlaps the strong one of iceberg 2 and cannot be detected by the LRM algorithm. For icebergs 4 and 5, no clear signatures were detected in RDSAR echoes mainly because the signatures are too close to the waveform leading edge where the noise level is larger in RDSAR.

The SARin detected signatures are irregularly spaced across-track and need to be re-sampled on a regular grid in order to geographically map the iceberg location, free-board and backscatter. The chosen grid is regular in the along- and across-track directions with an along-track resolution of 300 $m$ (i.e. the distance between two consecutive waveforms) and an across-track resolution of $50 \mathrm{~m}$. The latitude and across-track distance of each $\mathrm{CC}$ pixel are remapped on the regular grid using classical earth's projections. The icebergs free-board is presented in Figure 6-d and their contours are plotted in Figure 6-g for comparison with MODIS data. The icebergs characteristics are then estimated by analyzing the $\mathrm{CC}$ and regions properties of the remapped free-board and backscatter fields. Table 2 presents the iceberg area estimated from the remapped SARin data as well as the areas estimated from the manually supervised analysis of the MODIS image of Figure 6-a and the Sentinel 1 SAR images (Wide swath mode of Figure B.4-a).

Icebergs 1 to 4 , located between 0 and $3 \mathrm{~km}$ off-nadir, are very well detected and mapped compared to the MODIS and SAR images while the area 
Table 2: Characteristics of the detected icebergs in Cryosat-2 SARin data on Pass 2772 Cycle 9, 07/02/2015 22:10 UT; and iceberg areas from the analysis of MODIS and Sentinel-1 images. RCS: radar cross section.

\begin{tabular}{|c|c|c|c|c|c|c|c|c|c|c|c|c|c|}
\hline & \multirow{3}{*}{$\begin{array}{l}\text { lat } \\
\text { deg }\end{array}$} & \multirow{3}{*}{$\begin{array}{c}\text { Range } \\
\text { bin }\end{array}$} & \multicolumn{3}{|c|}{ SARin } & \multirow{3}{*}{$\begin{array}{c}\text { Max RCS } \\
\text { dB }\end{array}$} & \multirow{3}{*}{$\begin{array}{c}\text { SARin map } \\
\text { Area } \\
\mathrm{km}^{2}\end{array}$} & \multirow{3}{*}{$\begin{array}{l}\text { Lat } \\
\text { deg }\end{array}$} & \multicolumn{2}{|c|}{ RDSAR } & \multirow{3}{*}{$\begin{array}{l}\text { Area } \\
\mathrm{km}^{2}\end{array}$} & \multirow{3}{*}{$\begin{array}{c}\text { MODIS } \\
\text { Area } \\
\mathrm{km}^{2}\end{array}$} & \multirow{3}{*}{$\begin{array}{c}\text { Sentinel-1 } \\
\text { Area } \\
\mathrm{km}^{2}\end{array}$} \\
\hline & & & \multicolumn{2}{|c|}{ Area } & \multirow{2}{*}{$\begin{array}{c}\text { mean RCS } \\
\mathrm{dB}\end{array}$} & & & & Range & RCS & & & \\
\hline & & & pixel & $\mathrm{km}^{2}$ & & & & & bin & $\mathrm{dB}$ & & & \\
\hline 1 & 64.204 & 128 & 216 & $1.0-2.0$ & -4.1 & 5.3 & 0.9 & 64.201 & 153 & 7.35 & 1.5 & $1.1-1.18$ & 0.84 \\
\hline & 64.204 & 172 & 15 & & -7.0 & 0.4 & & & & & & & \\
\hline & 64.204 & 211 & 28 & & -4.8 & 5.0 & & & & & & & \\
\hline 2 & 64.160 & 98 & 16 & $0.65-1.2$ & -15.0 & -5.9 & 0.61 & 64.156 & 208 & 6.15 & 0.94 & $0.75-1.1$ & 0.33 \\
\hline & 64.160 & 133 & 49 & & -16.1 & -9.5 & & & & & & & \\
\hline & 64.160 & 181 & 32 & & -12.7 & -7.7 & & & & & & & \\
\hline & 64.160 & 208 & 45 & & -2.9 & 6.7 & & & & & & & \\
\hline 3 & 64.138 & 80 & 9 & $1.0-2.1$ & -10.2 & -5.4 & 0.55 & & & & & $0.6-1.1$ & 0.29 \\
\hline & 64.138 & 48 & 11 & & -14.3 & -11.7 & & & & & & & \\
\hline & 64.138 & 118 & 3 & & -15.8 & -14.9 & & & & & & & \\
\hline & 64.138 & 138 & 6 & & -15.4 & -13.6 & & & & & & & \\
\hline & 64.138 & 162 & 2 & & -18.7 & -18.6 & & & & & & & \\
\hline & 64.138 & 179 & 3 & & -14.2 & -13.1 & & & & & & & \\
\hline 4 & 64.127 & 177 & 38 & $0.4-0.8$ & -12.9 & -9.9 & 0.43 & & & & & $0.4-0.8$ & 0.21 \\
\hline & 64.127 & 197 & 5 & & -11.4 & -9.2 & & & & & & & \\
\hline & 64.127 & 214 & 5 & & -10.2 & -8.6 & & & & & & & \\
\hline 5 & 64.103 & 196 & 9 & $0.2-0.4$ & -11.6 & -10.3 & 0.13 & & & & & $0.8-1.2$ & 1.16 \\
\hline & 64.103 & 214 & 2 & & -9.6 & -9.6 & & & & & & & \\
\hline
\end{tabular}


of iceberg 5 located $5 \mathrm{~km}$ off-nadir, although detected, is largely underestimated. This iceberg is located at the limit of the across-track range detection window defined as a function of free-board elevation, $\delta$, and the time limits of the noise range part of the waveform, $t_{0}$ and $t_{1}$, by (Tournadre et al., 2008)

$$
\sqrt{\left(c t_{0}+2 \delta\right) H^{\prime \prime}} \geq d_{0} \geq \sqrt{\left(c t_{1}+2 \delta\right) H^{\prime \prime}}
$$

The comparison of the different area estimates given in Tables 2 SARin remapped, RDSAR, MODIS and Sentinel-1, shows the very good agreement of area estimates of the four eastern icebergs between SARin, RDSAR and MODIS. The Sentinel-1 SAR are significantly lower by $40 \%$ In a recent study comparing iceberg area estimate from SAR images and high resolution visible images Mazur et al. (2017a) also found that an area error about $48 \%$ for icebergs smaller than $0.5 \mathrm{~km}^{2}$ and about $20 \%$ for icebergs between 0.5 and $1 \mathrm{~km}^{2}$. For the western iceberg, only partly detected, the area is underestimated by both RDSAR and SARin method. A confidence index for the range limits of detection could be defined for each iceberg using Equation A.1 as

$$
C I=\frac{d_{0}-\sqrt{\left(c t_{0}+2 \delta\right) H^{\prime \prime}}}{\sqrt{\left(c t_{1}+2 \delta\right) H^{\prime \prime}}-\sqrt{\left(c t_{1}+2 \delta\right) H^{\prime \prime}}}
$$

CI should be between 0 and 1 . The two area estimates of the RDSAR detected iceberg are almost identical to the SARin ones. This validates the simplified model used to infer area from range and backscatter.

Table 3 presents the area, mean and max free-boards and mean and max backscatters of the five icebergs. The maximum backscatter for iceberg 1 is as in SAR mode case underestimated compared to the RDSAR, but for iceberg 2 the maximum backscatter is larger in SARin mode than that in 
Table 3: Iceberg characteristics from SARin analysis

\begin{tabular}{cccccc}
\hline iceberg number & 1 & 2 & 3 & 4 & 5 \\
\hline Area $\left(\mathrm{km}^{2}\right)$ & 0.9 & 0.61 & 0.55 & 0.43 & 0.13 \\
mean free-board $(\mathrm{m})$ & 26.1 & 22.8 & 36.5 & 20.6 & 27.9 \\
max free-board $(\mathrm{m})$ & 36.3 & 38.9 & 49.1 & 25.6 & 29.5 \\
mean backscatter $(\mathrm{dB})$ & -7.1 & -6.5 & -13.5 & -12.2 & -11.9 \\
max backscatter $(\mathrm{dB})$ & 3.8 & 4.5 & -9.2 & -8.8 & -10.9 \\
\hline
\end{tabular}

RDSAR. This might be related to the specularity of the echo.

The use of interferometry allows for the first time a direct estimate of the iceberg free-board. The mean iceberg free-board given in Table 3 ranges from 20.6 to $36.5 \mathrm{~m}$ while the maximum free-board ranges from 25.6 to $49.1 \mathrm{~m}$. Except for iceberg 3, the mean free-board is within a $20-30 \mathrm{~m}$ range, i.e. of the same order of magnitude as the $28 \mathrm{~m}$ free-board chosen as constant free-board for the RDSAR area estimate. The processing of the complete Cryosat-2 archive will allow to better estimate the free-board distribution for both Greenland and Southern Ocean icebergs and to improve the area-backscatter relationship. The mean free-boards are also well within the range of free-boards observed by ship radar in Eastern Greenland for large icebergs (<600 m length) presented by Dowdeswell et al. (1992). The across-track SARin resolution is high enough to allow the description of the iceberg complex topography as it can be seen in Figure 7 which presents the free-board for iceberg 1 . Iceberg 1 is composed of a lower section whose elevation is about $18 \mathrm{~m}$ and a higher one about $30 \mathrm{~m}$ elevation with several spikes culminating at $40 \mathrm{~m}$. Some of the spikes are associated with very high 
backscatter while flatter surface are associated with low backscatter. The comparison with the coincident SAR and MODIS images (Figure 7-c and -d) shows not only a good agreement for the size of the iceberg but also for the backscatter distribution over the iceberg.

\section{Conclusion}

Cryosat-2 is the first altimeter to operate in three different modes over the ocean. Over most of the ocean it operates in the pulse limited LRM mode used by all past altimeters. The method of iceberg detection developed by Tournadre et al. (2008) can be applied without modification and is currently used in the ALTIBERG small iceberg data base. The iceberg area is estimated from the iceberg backscatter and range using a backscatter model under hypotheses of constant free-board and ice backscatter. The LRM detection can also be applied to the pseudo-LRM or RDSAR waveforms computed from the SAR and SARin mode data. For Cryosat-2, RDSAR data are only available for a limited number of SAR and SARin orbits, but they are now part of the standard Sentinel-3 SAR data processing and both SAR and RDSAR are provided in Level 1 products. It will thus be possible to directly compare the detection and iceberg characteristics from both modes and thus to ensure the continuity and homogeneity between altimeters operating in different modes.

The stacking process used to compute SAR waveforms significantly reduces the noise level of the waveform thermal noise part. This noise reduction facilitates the detection especially for smaller icebergs whose backscatter is too low to come out of RDSAR noise. The LRM parabolic signature of 
icebergs reduces to bright spots in SAR data that can be easily detected using classical connected components and region properties algorithms. The iceberg area can be estimated using the along-track width and across-track length of the signature. However, as the across-track altimeter resolution strongly varies with the distance from nadir, only crude area estimates can be made and the RDSAR method based on range and backscatter appears more robust.

In SARin mode, both SAR and RDSAR echoes can be used to detect icebergs. Although the SNR is strongly reduced compared to SAR because of the reduction of the Burst mode Pulse Repetition Frequency (from $85.7 \mathrm{~Hz}$ to $21.4 \mathrm{~Hz}$ ), the coherence can be used to improve the detection by limiting the probability of false alarm and by insuring the presence of a target above the sea surface. Furthermore, in this mode the range analysis window is four times larger than that in LRM and SAR mode. The number of range bins that can be used for detection is significantly larger, which almost double the detection swath of the altimeter from about $6 \mathrm{~km}$ to $12 \mathrm{~km}$. The main interest of SARin mode is the possibility, for the first time for a satellite sensor, to precisely locate the surface scatterer and to allow the estimation of iceberg free-board and thus volume. The very high across-track accuracy also allows to map the iceberg topography at an unprecedented resolution.

Over the ocean where icebergs are more frequently present, i.e. near sea-ice covered regions, Cryosat-2 operates mainly in SAR mode. In the near future the SAR archive will be fully processed and included after intercalibration with other altimeters in the ALTIBERG data set. The SARin mode is certainly the most powerful existing sensor to detect and characterize 
small icebergs. Up to now only limited oceanic regions, around Greenland or near Antarctica during Austral summers, are sampled in SARin mode. However, the processing of the SARin archive will provide a unique iceberg data-set that can be used to study the iceberg distributions of free-board, size, area, length.

\section{Appendix A. LRM detection}

The method of detection of iceberg using pulse limited altimeter data was presented in detail by Tournadre et al. (2008) and is here briefly summarized. An altimeter is a nadir looking radar that emits short pulses that are backscattered by the sea surface. The altimeter measures the backscattered power as a function of time to construct the echo waveform from which the geophysical parameters are estimated. For Cryosat, the waveform range analysis window is 128 bins of 3.125 ns (i.e. the compressed pulse length) long or $60 \mathrm{~m}$. A detailed description of the principles of the pulse limited altimetry is given for example in Chelton et al. (2001). A point target of height $\delta$ above sea level located at distance $d_{0}$ from the satellite nadir will give an echo in the thermal noise part (i.e. above the mean sea surface) of an altimeter waveform at the time $t_{i}$ defined by (Powell et al., 1993)

$$
\frac{c t_{i}}{2}=-\delta+\frac{1}{2} \frac{R_{E}+H}{R_{E} H} d_{0}^{2}=-\delta+\frac{d_{0}^{2}}{2 H^{\prime \prime}}
$$

where $c$ is the celerity of light, $R_{E}$ the earth's radius, $H$ the satellite altitude, and $H^{\prime \prime}=H /\left(1+H / R_{E}\right)$ is the reduced satellite height. In the waveform space the signature of a point target is thus purely deterministic, i.e. a parabola as a function of time when the satellite flies over the target. A 
target is detectable if its echo time, $t_{i}$ lies within the waveform range window and if its backscatter coefficient is significantly larger than the thermal noise of the sensor. The detection algorithm is based on the automated detection of parabolas in the waveform noise part using the convolution product $C$ between a filter, $F$ characteristic of a target signature, and the thermal noise part of the waveforms.

$$
C(k, l)=\sum_{n=1}^{N_{1}} \sum_{m=1}^{M_{2}} \sigma_{0}(k, l) F(k-n, l-m)
$$

where $k$ is the telemetry sample index, $N_{1}$, the number of range bins used for detection, $l$, the along-track waveform index, and $\sigma_{0}$, the echo power. For each waveform of the detected parabola, the maximum of correlation $C(l)$ and its location $k_{\max }^{C}(l)$ (i.e. the range), and the maximum of backscatter, $\sigma_{\max }(l)$ and its location $k_{\max }^{\sigma}(l)$ are determined. A waveform is assumed to contain an iceberg signature if $C_{\max }(l)$ and $\sigma_{\max }(l)$ are larger than given thresholds $C_{1}$ and $\sigma_{1}$ determined empirically by analysis of hundreds of signatures. The iceberg range $t_{e c h}$ depends on the distance $d$ from nadir of the iceberg center and on the iceberg's free-board elevation $h$ while its backscatter $\sigma_{i c e b}$ depends on the area, $A$, the distance from nadir $d$, the backscattering coefficient of the iceberg surface, $\sigma_{0}^{i c e}$, which is conditioned by the ice characteristics, the shape and roughness of the iceberg surface, and the presence of snow or water on the iceberg surface. $t_{e c h}$ and $\sigma_{i c e b}$ are function of four main unknowns, $d$, $A, h$ and $\sigma_{0}^{i c e}$. The iceberg area can be estimated if assumptions are made on the values of two of the remaining unknowns $\left(d, h, \sigma_{0}^{i c e}\right) . \sigma_{0}^{i c e}$ is assumed to be constant for all icebergs and set at $21 \mathrm{~dB}$ (Tournadre et al., 2012). Following Gladstone et al. (2001) and Romanov et al. (2012) the free-board 
elevation for icebergs larger than $200 \mathrm{~m}$, is set at $28 \mathrm{~m}$ corresponding to a mean iceberg thickness of $250 \mathrm{~m}$. Using these assumptions, the signature of square icebergs as a function of distance from nadir, (0 to $12 \mathrm{~km})$, and area (0.01 to $9 \mathrm{~km}^{2}$ ) for each altimeter is computed using an analytic model of waveform. The range $t_{e c h}=f(d, A)$ and the mean backscatter $\sigma_{i c e b}=g(d, A)$ are estimated from the modeled waveforms and used to compute an inverse model $A=l\left(t_{e c h}, \sigma_{i c e b}\right)$ and $d=m\left(t_{e c h}, \sigma_{i c e b}\right)$ for each altimeter.

\section{Appendix B. Sensitivity of the SAR and SARIn detection to the power and coherence thresholds}

The SAR detection algorithm relies on the rms threshold used to binarize the normalized waveforms. The sensitivity of the method to this threshold has been tested using values from 3 to 6 rms (by 0.1 steps) for Cycle 9 pass 2889. The results of the detection, area and backscatter estimate are presented in figure B.1. The threshold has no impact on the detection and none on the iceberg maximum backscatter. Low thresholds $(<3.6)$ leads to an obvious overestimation of the area of the smallest iceberg (\#3) estimated using equation 3 . The underestimation of the mean backscatter for icebergs 1 and 2 reflect the inclusion of water pixel in the signature. Thresholds from 4 to 5 give very similar results for both area and backscatter with an rms smaller than $3 \%$ for area estimate and $2.8 \%$ for the mean backscatter. The threshold has been set to $4 \mathrm{rms}$.

The SARIn algorithm is similar to the SAR one and includes a second threshold on coherence in the waveform binarization. The rms threshold has been tested in the same way as previously with very similar results (not 
presented here) for the Cycle 9 Pass 2772. For rms threshold above 3.5 there is almost no impact on the detection and parameter estimates. Coherence thresholds from 0.5 to 0.85 (by 0.1 steps) have been tested (using a rms threshold of 4) and the results are presented in figure B.2. Thresholds larger than 0.7 fail to detect iceberg 5 and those larger than 0.74 iceberg 3 . For thresholds between 0.5 and 0.7 , the rms of the area, mean freeboard and max backscatter are smaller than 18, 16 and $8 \%$ respectively.

The area estimates were also compared to the ones manually obtained from the analysis of the 6 MODIS images (from Aqua and Terra satellites) (see figure B.3) and the 2 Sentinel 1 SAR images (Wide swath mode see figure B.4) available the same day as the Cryosat-2 pass. Iceberg 5 which lies at the limit of the Cryosat swath is not considered in the following. The resolution of the MODIS images $(250 \mathrm{~m})$ is similar to the along-track Cryosat resolution (300m) while the SAR images one $(40 \mathrm{~m})$ is similar to Cryosat across-track one $(50 \mathrm{~m})$. The MODIS estimates are quite scattered mainly because of the low resolution and of the impact of the solar angle and of the viewing incidence. However, there is an overall good agreement between the mean MODIS areas and the SARin ones for threshold between 0.55 and 0.65. The Sentinel 1 images presented in figure B.4 clearly show the presence of the 5 icebergs. They are quite difficult to analyze because of the low contrast between ice and water for some part of the iceberg in both $\mathrm{HH}$ and $\mathrm{HV}$ polarizations. The SAR estimated areas are significantly lower (by $\sim 40 \%$ ) than the MODIS and SARin ones. Coherence around 0.7 would give results comparable to SAR images. However, we choose to set the threshold to 0.6 as a trade-off between MODIS and SAR images estimates. In an operational 
method the use of two thresholds can be used to give a first estimate of the method precision.

Sentinel-1 SAR images were provided by the European Space Agency. The study was partly funded by The French Centre National d'Etudes Spatiales. The MODIS data were provided by NASA. The ALTIBERG data set is available at the CERSAT web site: http://cersat.ifremer.fr/user-community/news/item/473altiberg-a-database-for-small-icebergs.

\section{References}

Bouzinac, C., 2012. Cryosat Product handbook. European Space Agency, ESRIN, Frascati, Italy.

Boy, F., Desjonquéres, J. D., Picot, N., Moreau, T., Raynal, M., 2016. Cryosat-2 sar-mode over oceans: Processing methods, global assessment, and benefits. IEEE Trans. Geoscienc. Rem. Sen. PP (99), 1-11.

Chelton, D. E., Ries, J. C., Haines, B. J., Fu, L.-L., Callahan, P. S., 2001. Satellite Altimetry and Earth Science: A Handbook of Techniques and Applications. Academic Press, San Diego, Ch. I: An Introduction to Satellite Altimetry, p. 463 pp.

Denbina, M., Collins, M. J., 2014. Iceberg detection using simulated dualpolarized radarsat constellation data. Canadian J. Remote Sens. 40 (3), $165-178$.

Depoorter, M. A., Bamber, J. L., Griggs, J. A., Lenaerts, J. T. M., Ligtenberg, S. R. M., van den Broeke, M. R., Moholdt, G., 2013. Calving fluxes and basal melt rates of Antarctic ice shelves. Nature 502. 
Dinardo, S., 2013. Guidelines for the SAR (Delay-Doppler) L1b Processing. Tech. Rep. XCRY-GSEG-EOPS-TN-14-0042, European Space Agency, Frascati, Italy.

Dowdeswell, J. A., Whittington, R. J., Hodgkins, R., 1992. The sizes, frequencies, and freeboards of east greenland icebergs observed using ship radar and sextant. J. Geophys. Res. : Oceans 97 (C3), 3515-3528.

Enderlin, E. M., Howat, I. M., Jeong, S., Noh, M.-J., van Angelen, J. H., van den Broeke, M. R., 2014. An improved mass budget for the greenland ice sheet. Geophys. Res. Let. 41 (3), 866-872.

ESA-ESTEC, 2007. CryoSat Mission and Data Description, CS-RP-ESA-SY0059,Issue 3. European Space Agency, ESTEC, Noordwijk, The Netherlands.

Galin, N., Wingham, D. J., Cullen, R., Fornari, M., Smith, W. H. F., Abdalla, S., Jan 2013. Calibration of the Cryosat-2 interferometer and measurement of across-track ocean slope. IEEE Trans. Geoscienc. Remote Sens. 51 (1), 57-72.

Gill, R., 2001. Operational detection of sea ice edges and icebergs using sar. Canadian J. Remote Sens. 27 (5), 411-432.

Gladstone, R., Bigg, G., 2002. Satellite tracking of icebergs in the weddell sea. Antarctic Science 14, 278-287.

Gladstone, R. M., Bigg, G. R., Nicholls, K. W., 2001. Iceberg trajectory modeling and meltwater injection in the Southern Ocean. J. Geophys. Res. 106, 19903-19916. 
Gómez-Enri, J., Scozzari, A., Soldovieri, F., Coca, J., Vignudelli, S., 2016. Detection and characterization of ship targets using cryosat-2 altimeter waveforms. Remote Sensing 8 (3), 193.

Gommenginger, C., Martin-Puig, C., Amarouche, L., Raney, R. K., 2013. Review of state of knowledge for SAR altimetry over ocean. Tech. Rep. EUM/RSP/REP/14/749304, EUMETSAT, Darmstadt, Germany.

Green, C. L., Green, J. A. M., Bigg, G. R., 2011. Simulating the impact of freshwater inputs and deep-draft icebergs formed during a MIS 6 Barents Ice Sheet collapse. Paleoceanography 26 (2), A2211.

Hemming, S. R., 2004. Heinrich events: Massive late pleistocene detritus layers of the north Atlantic and their global climate imprint. Rev. Geophys. $42,1-43$.

Jensen, J., Apr 1999. Angle measurement with a phase monopulse radar altimeter. IEEE Trans. Antennas Propag. 47 (4), 715-724.

Jongma, J. I., Driesschaert, E., Fichefet, T., Goosse, H., Renssen, H., 2009. The effect of dynamic-thermodynamic icebergs on the Southern Ocean climate in a three-dimensional model. Ocean Mod. 26 (1-2), 104-113.

Marino, A., Dierking, W., Wesche, C., Sept 2016. A depolarization ratio anomaly detector to identify icebergs in sea ice using dual-polarization sar images. IEEE Trans. Geoscienc. Rem. Sens. 54 (9), 5602-5615.

Mazur, A., Wåhlin, A., Krezel, A., 2017a. An object-based SAR image iceberg detection algorithm applied to the Amundsen Sea. Rem. Sens. Envir. $189,67-83$. 
Merino, N., Sommer, J. L., Durand, G., Jourdain, N. C., Madec, G., Mathiot, P., Tournadre, J., 2016. Antarctic icebergs melt over the southern ocean : Climatology and impact on sea ice. Ocean Mod. 104, 99-110.

Nanda, S., 2015. Multiple scatterer retracking and interferometric swath processing of CryoSat-2 data for ice sheet elevation changes. Master's thesis, Dpt. Geoscience \& Remote Sensing, Fac. Civil Engineering and Geosciences, Technical University Delft, The Netherlands.

Powell, R. J., Birks, A. R., Wrench, W. J., Biddiscombe, C. L., 1993. Using transponders with ERS1-1 and Topex altimeters to measure orbit altitude to $\pm 3 \mathrm{~cm}$. In: Proc. First ERS- Symposium (ESA SP-359). pp. 511-516.

Raney, R., Sep 1998. The delay/Doppler radar altimeter. IEEE Trans. Geoscienc. Rem. Sens. 36 (5), 1578-1588.

Ray, C., Martin-Puig, C., Clarizia, M. P., Ruffini, G., Dinardo, S., Gommenginger, C., Benveniste, J., Feb 2015. SAR Altimeter backscattered waveform model. IEEE Trans. Geoscienc. Rem. Sens. 53 (2), 911-919.

Rignot, E., Jacobs, S., Mouginot, J., Scheuchl, B., 2013. Ice-shelf melting around Antarctica. Science 341, 266-270.

Romanov, Y., Romanova, N. A., Romanov, P., 2012. Shape and size of Antarctic icebergs derived from ship observation data. Antarctic Science $24,77-87$.

Silva, T., Bigg, G., 2005. Computer-based identification and tracking of antarctic icebergs in sar images. Remote Sens. Envir. 94, 287-297. 
Silva, T., Bigg, G., Nicholls, K., 2006. The contribution of giant icebergs to the Southern Ocean freshwater flux. J. Geophys. Res. 111, C03004.

Smal, I., Loog, M., Niessen, W., Meijering, E., Feb 2010. Quantitative comparison of spot detection methods in fluorescence microscopy. IEEE Trans. Med. Imag. 29 (2), 282-301.

Smith, K. L., JUN 2011. Free-drifting icebergs in the Southern Ocean: An overview. Deep Sea Res. Part II-Topical studies in Oceanography 58 (1112), 1277-1284.

Tournadre, J., Bouhier, N., Girard-Ardhuin, F., Remy, F., JAN 2016. Antarctic icebergs distributions 1992-2014. J. Geophys. Res. 121 (1), 327-349.

Tournadre, J., Girard-Ardhuin, F., Legresy, B., MAY 1 2012. Antarctic icebergs distributions, 2002-2010. J. Geophys. Res. 117, C05004.

Tournadre, J., Whitmer, K., Girard-Ardhuin, F., AUG 23 2008. Iceberg detection in open water by altimeter waveform analysis. J. Geophys. Res. 113 (C8), C08040.

Wesche, C., Dierking, W., 2012. Iceberg signatures and detection in sar images in two test regions of the weddell sea, antarctica. J. Glaciology 58 (208), 325-339.

Wingham, D., Francis, C., Baker, S., Bouzinac, C., Brockley, D., Cullen, R., de Chateau-Thierry, P., Laxon, S., Mallow, U., Mavrocordatos, C., Phalippou, L., Ratier, G., Rey, L., Rostan, F., Viau, P., Wallis, D., 2006. CryoSat: A mission to determine the fluctuations in earth's land and 
${ }_{648}$ marine ice fields. Adv. Space Res. 37 (4), 841-871, natural Hazards and ${ }_{649}$ Oceanographic Processes from Satellite Data. 

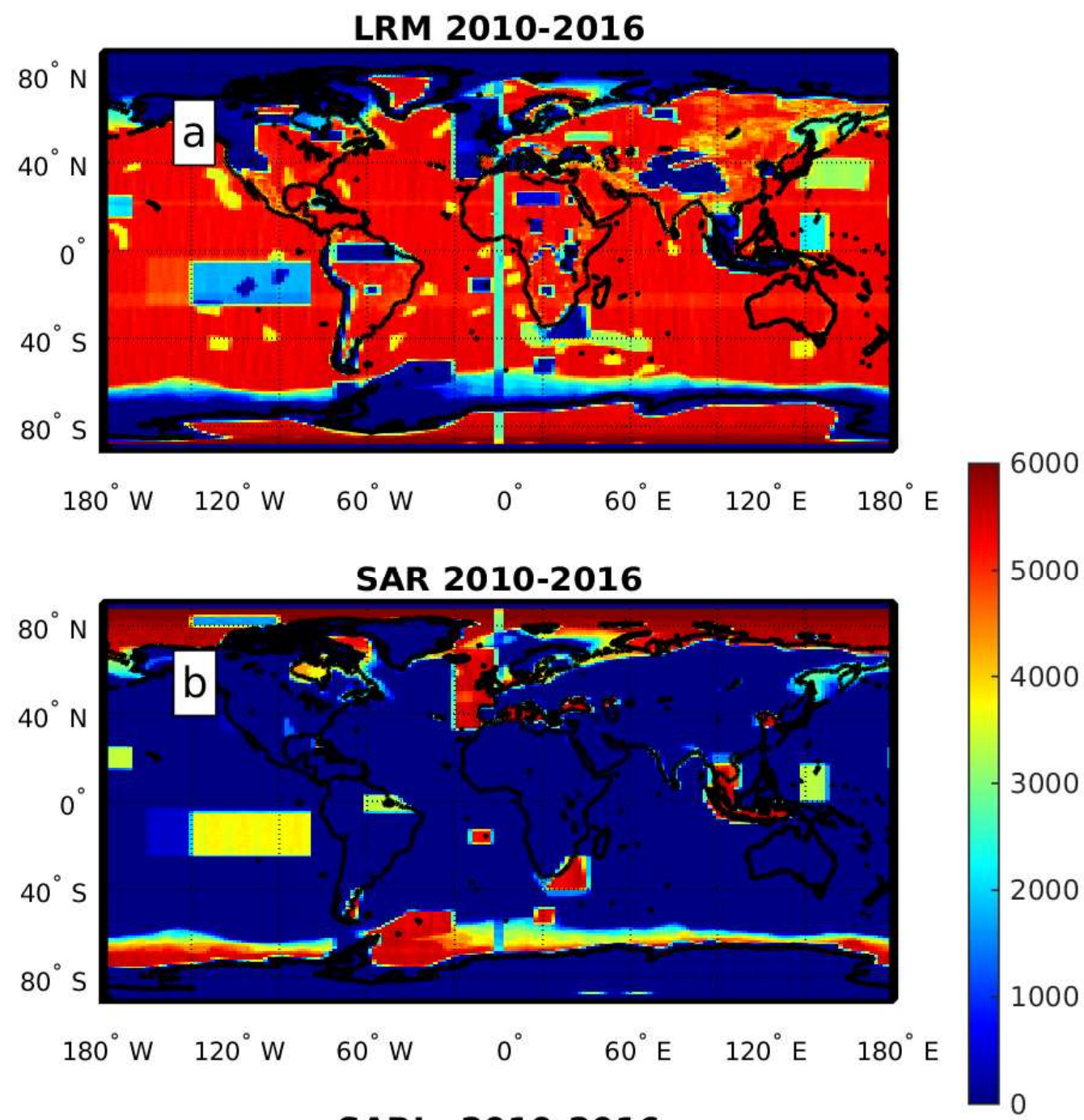

SARIn 2010-2016

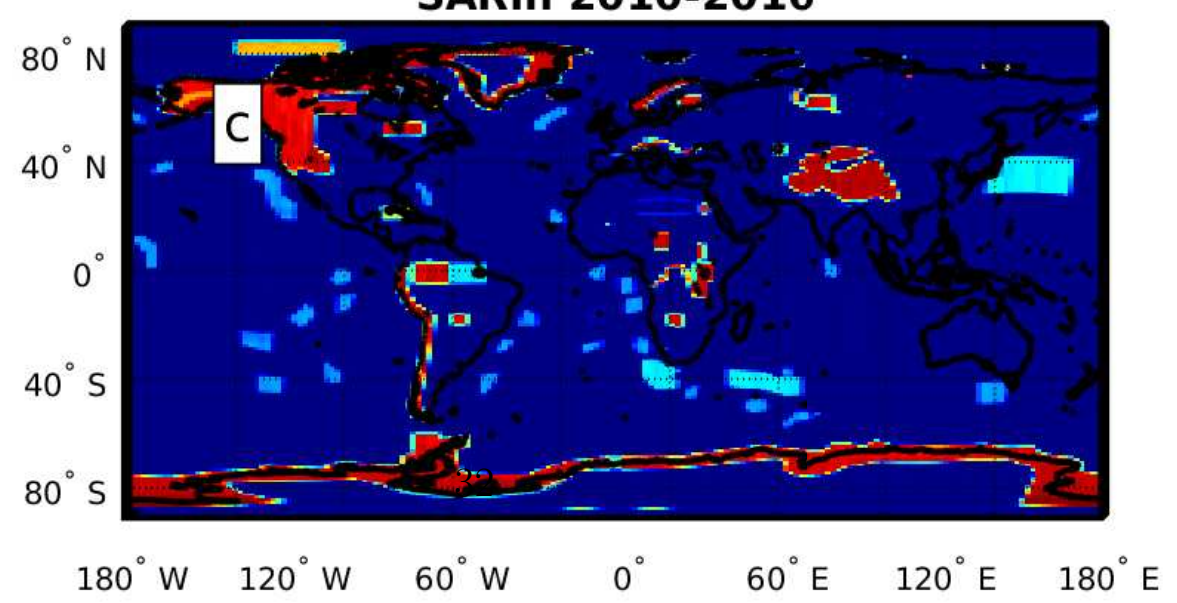




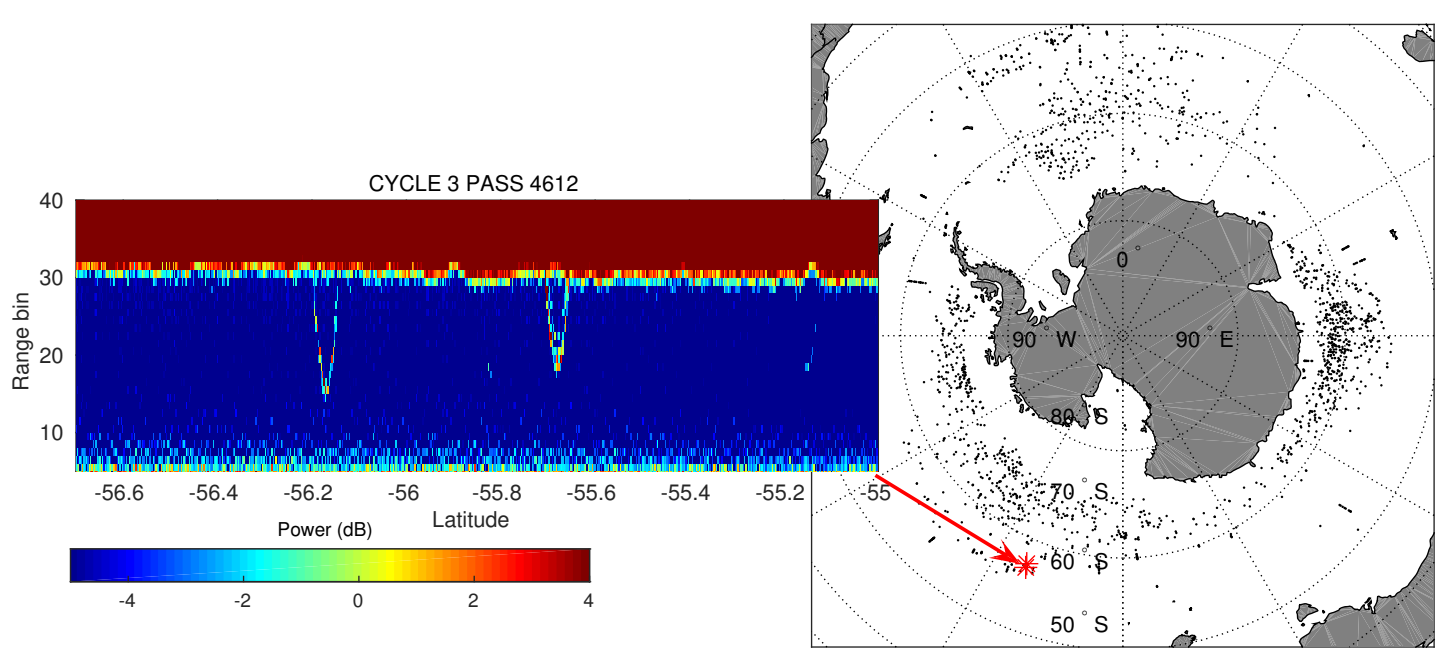

Figure 2: Icebergs detected using Cryosat-2 LRM data from 2010 to 2016 (black points). The left plot presents the signature of two icebergs detected in the South Pacific (red crosses) in the LRM waveforms (power in $\mathrm{dB}$ ) of pass 4612 cycle 3. 


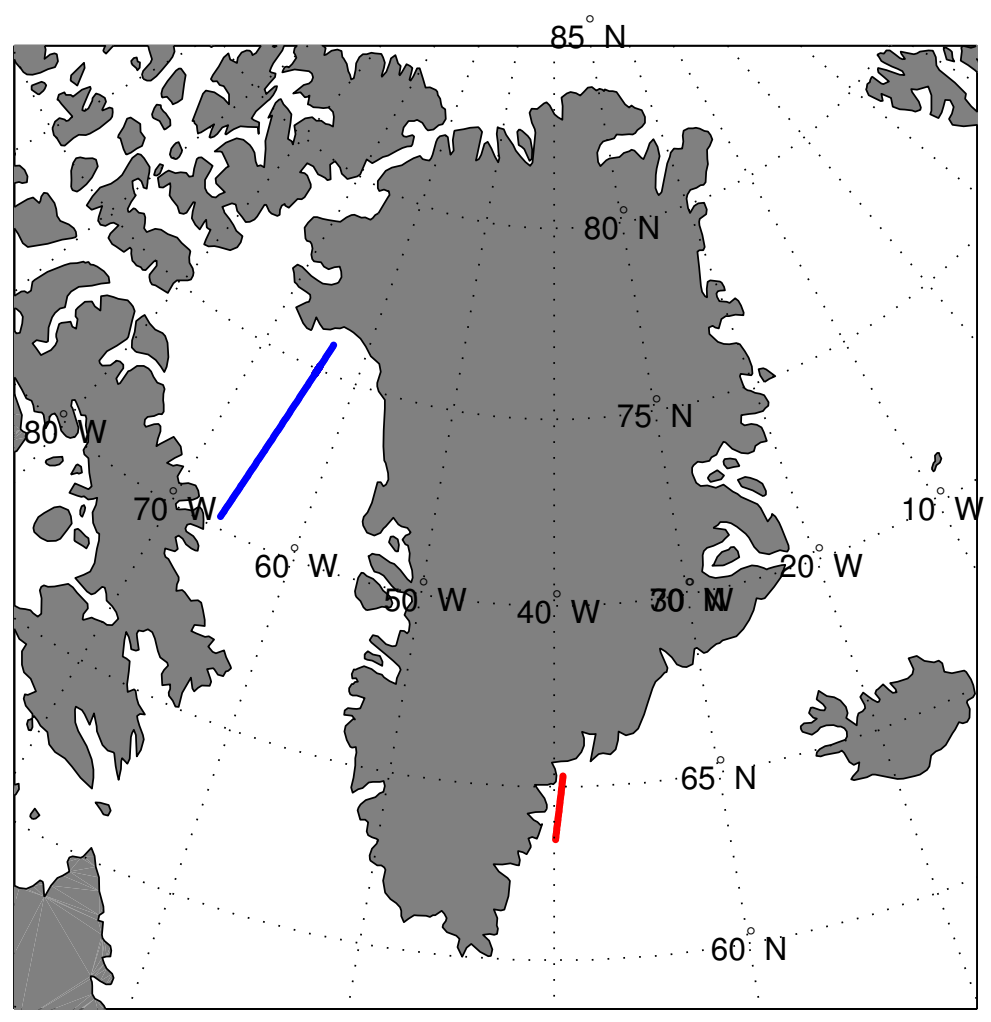

Figure 3: Location of the SAR (blue line) and SARin (red line) passes used for iceberg detection. 

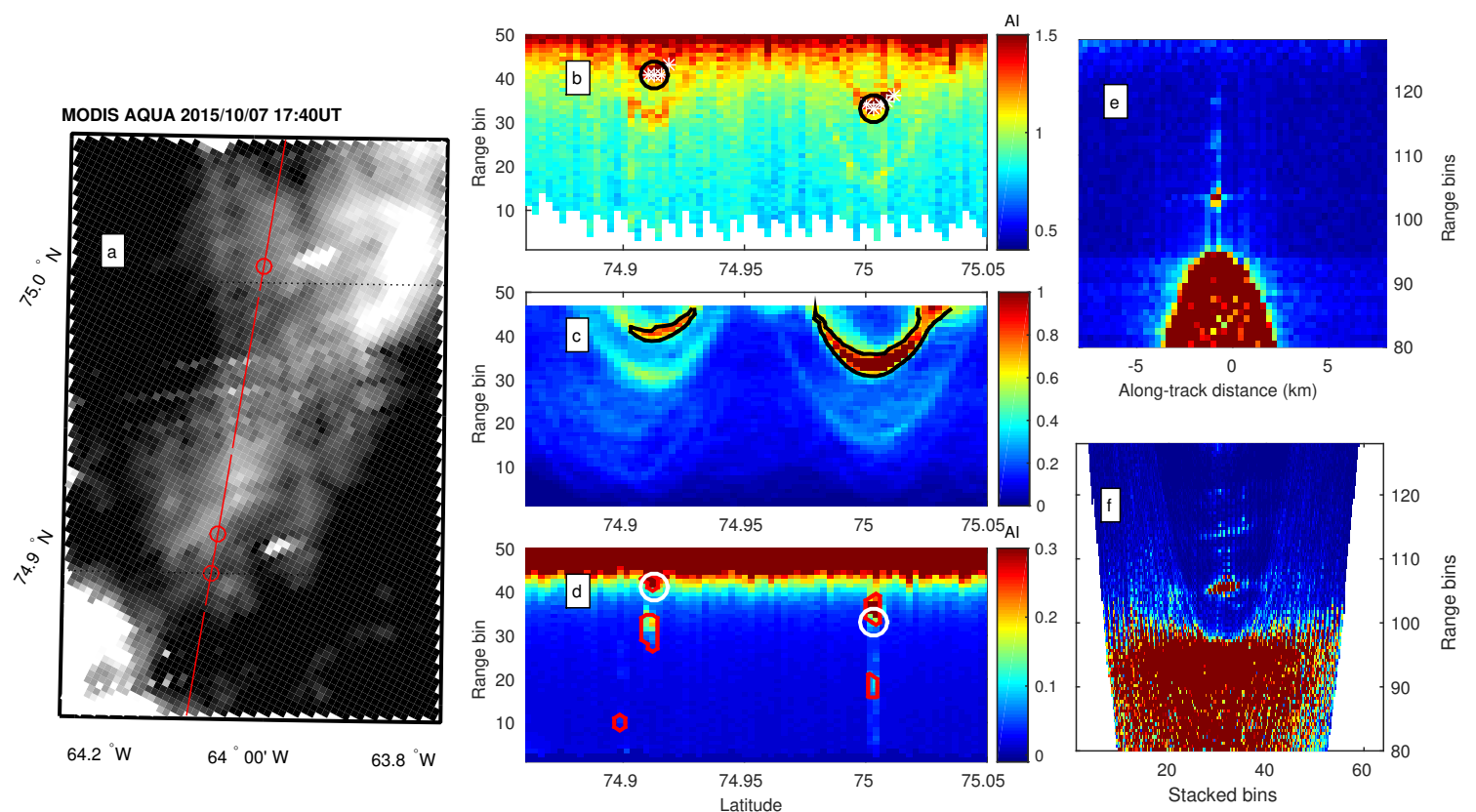

Figure 4: Example of detection of iceberg using SAR mode data (pass 2889 cycle 9, 2015/10/07 23:36 UT). (a) Aqua MODIS visible images at $250 \mathrm{~m}$ resolution on 2015/10/07 17:40 UT. The red line represents the altimeter ground track and the red circles the SAR detected icebergs. (b) Reduced SAR $20 \mathrm{~Hz}$ waveforms. The black circles indicate the detected icebergs and the white stars the position of the local echoes maximums. (c) Product of convolution between the filter and the RDSAR waveform used for detection, the black isoline represents the local maximums of correlation. (d) SAR $20 \mathrm{~Hz}$ waveforms. The red isolines show the SAR detected icebergs and the white circles the RDSAR ones. (e) Delay/Doppler map at $75^{\circ} \mathrm{N}$. (f) Stacked Doppler beams at $75^{\circ} \mathrm{N}$. 


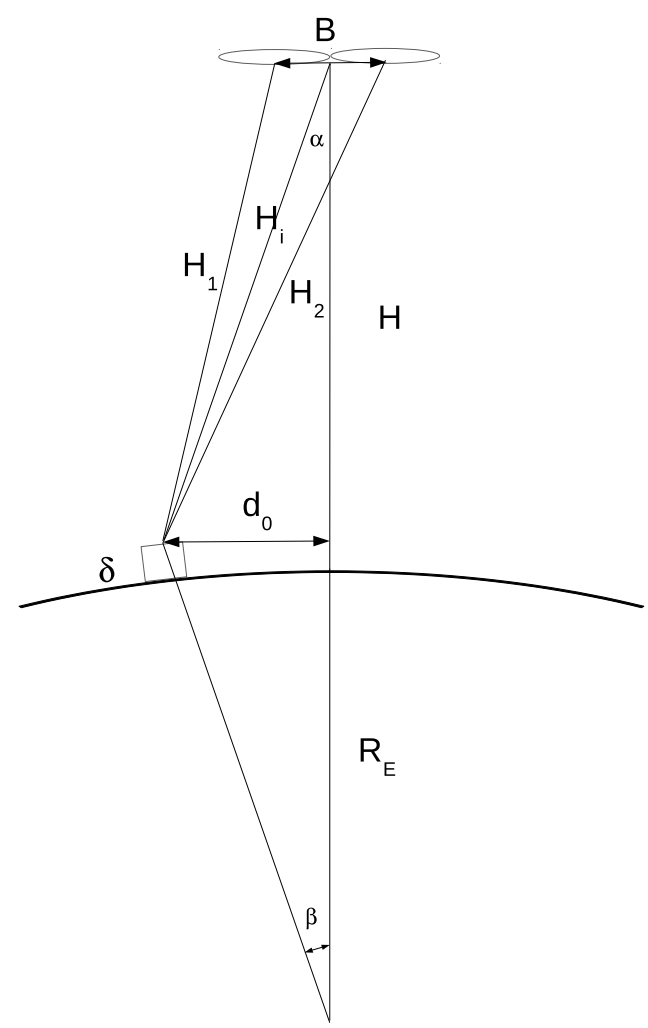

Figure 5: Cryosat-2 SARIn geometry. B: Baseline, i.e. distance between the two antennas, $d_{0}$ distance of the iceberg from nadir, $\delta$ iceberg's free-board, $R_{E}$ earth's radius, $H$ satellite altitude, $H_{1}, H_{2}$ ranges of iceberg for the two antennas. $\alpha$ off-nadir angle. 

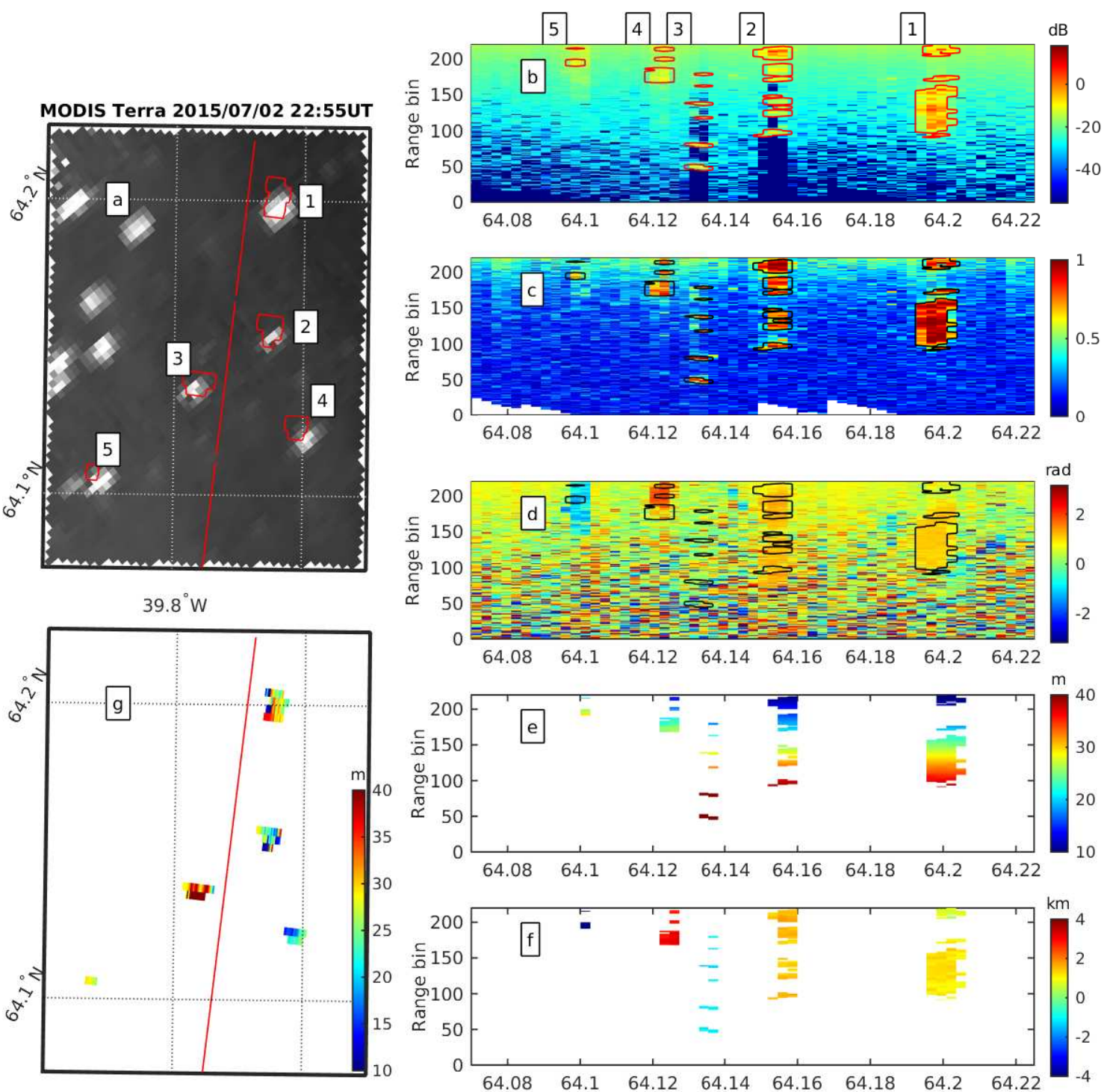

$39.8^{\circ} \mathrm{W}$
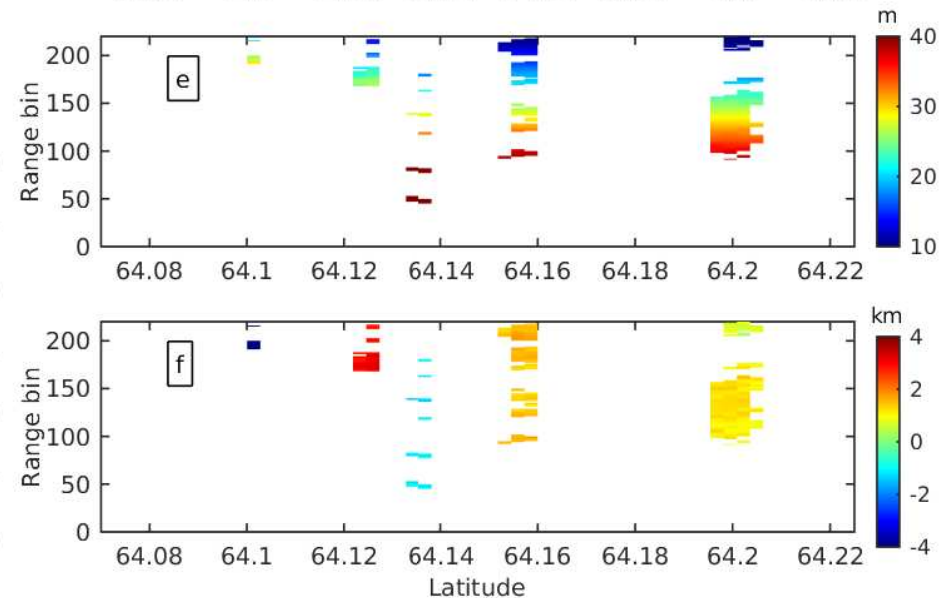

Figure 6: Iceberg detection using SARin data Cycle 9 Pass 2772, July 2nd 2015 22:10 UT. (a) MODIS Terra image on July 2nd 2015 22:55 UT. (b) SAR waveforms (in dB). (c) Interchannel coherence. (d) Phase difference (in rad).(e) free-board of the detected icebergs (in m). (g) Iceberg free-board remapped on a regular grid (in $\mathrm{m}$ ). The red or black isolines represent the detected icebergs. 

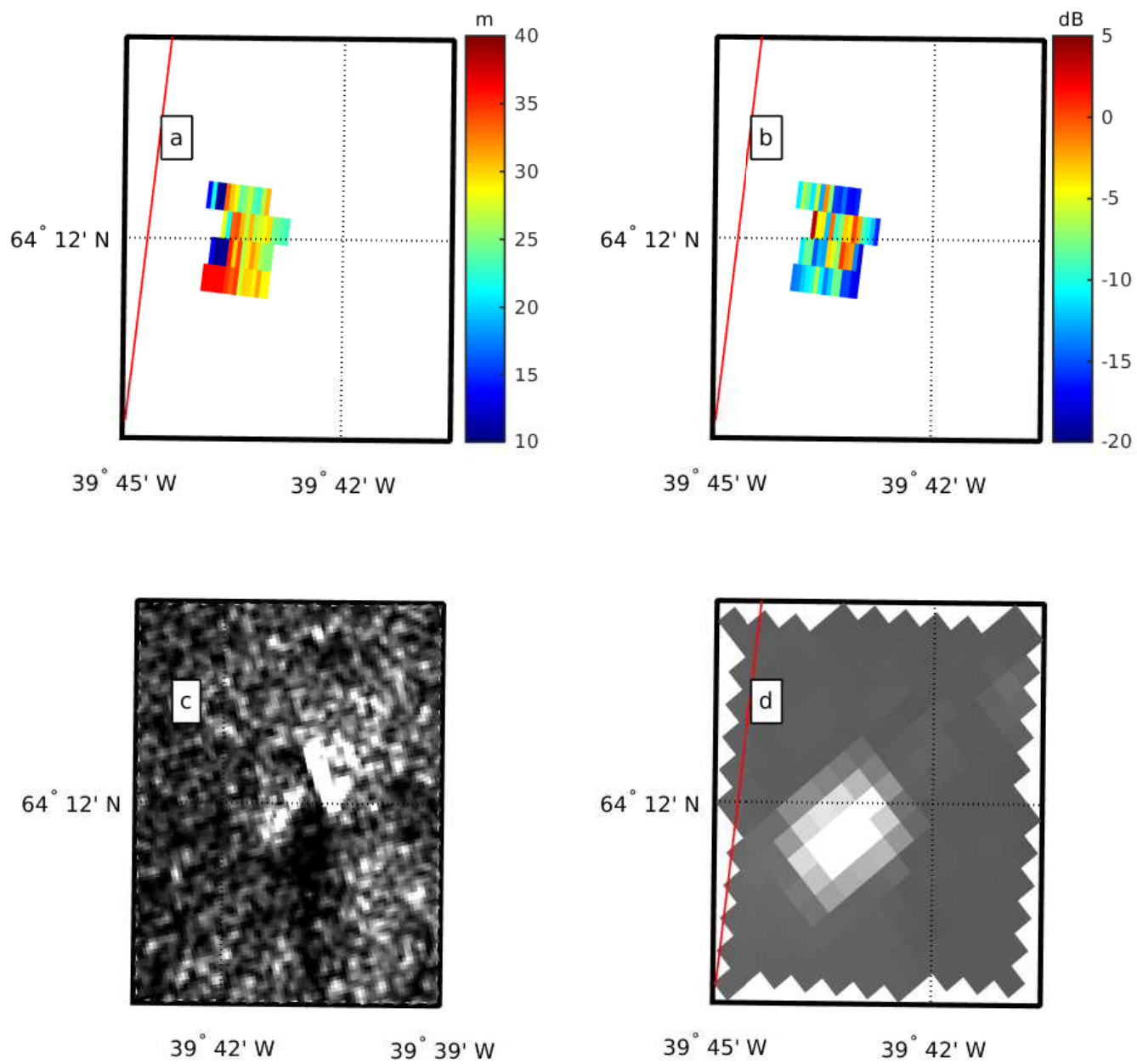

Figure 7: Detail of Iceberg 1 of Figure 6: (a) free-board (m). (b) Backscatter (dB) from Cryosat-2 on 07/02/2015 22:10UT. (c) Sentinel-1 SAR image on 07/01/2015 09:23 UT. (d) Detail of MODIS Terra image of figure 7-a (07/02/2015 22:55 UT). 

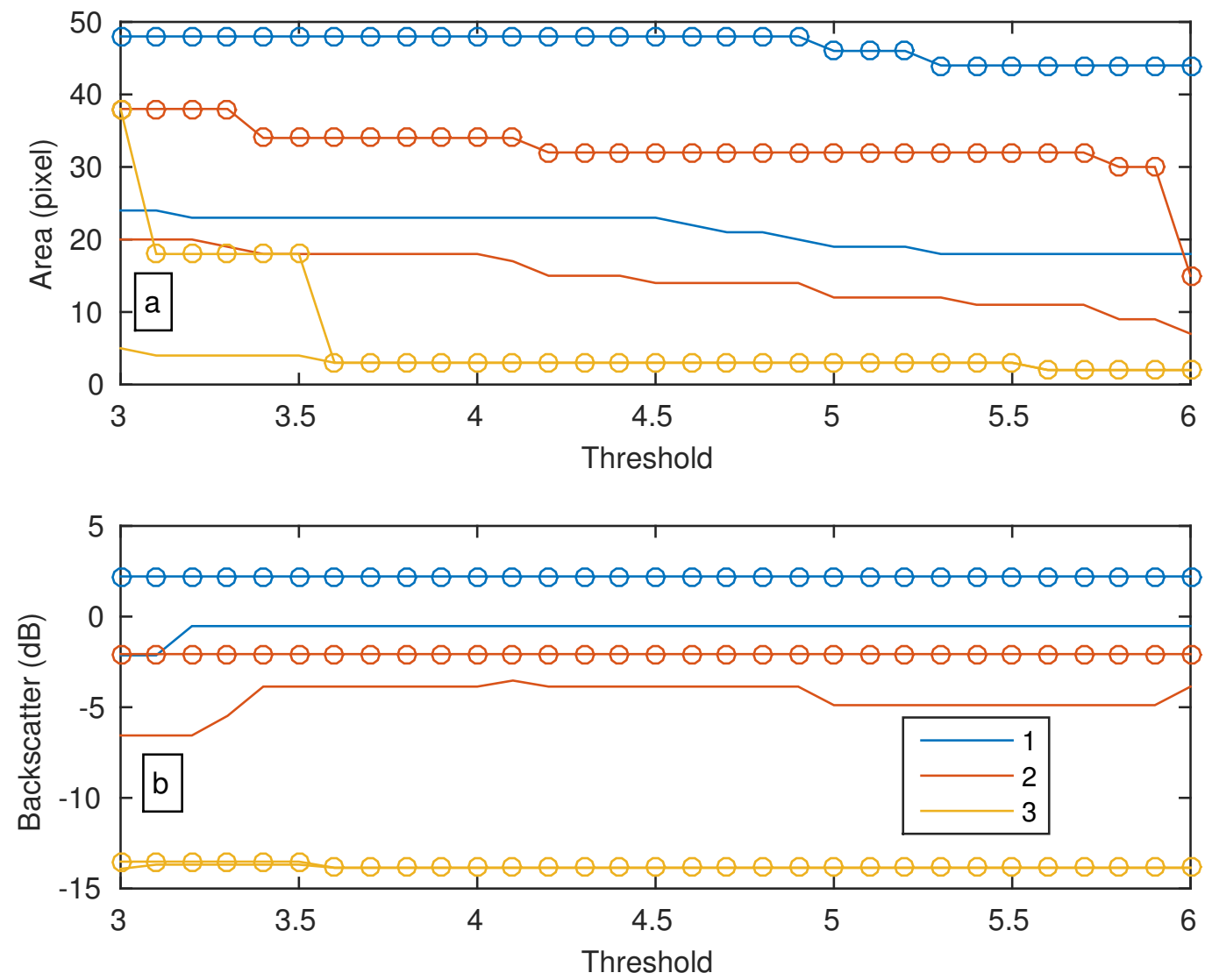

Figure B.1: (a) Iceberg signature areas using equations 2 (solid lines) and 3 (circles) as a function of rms threshold. (b) Mean (solid line) and maximum (circles) backscatter of the detected icebergs. 

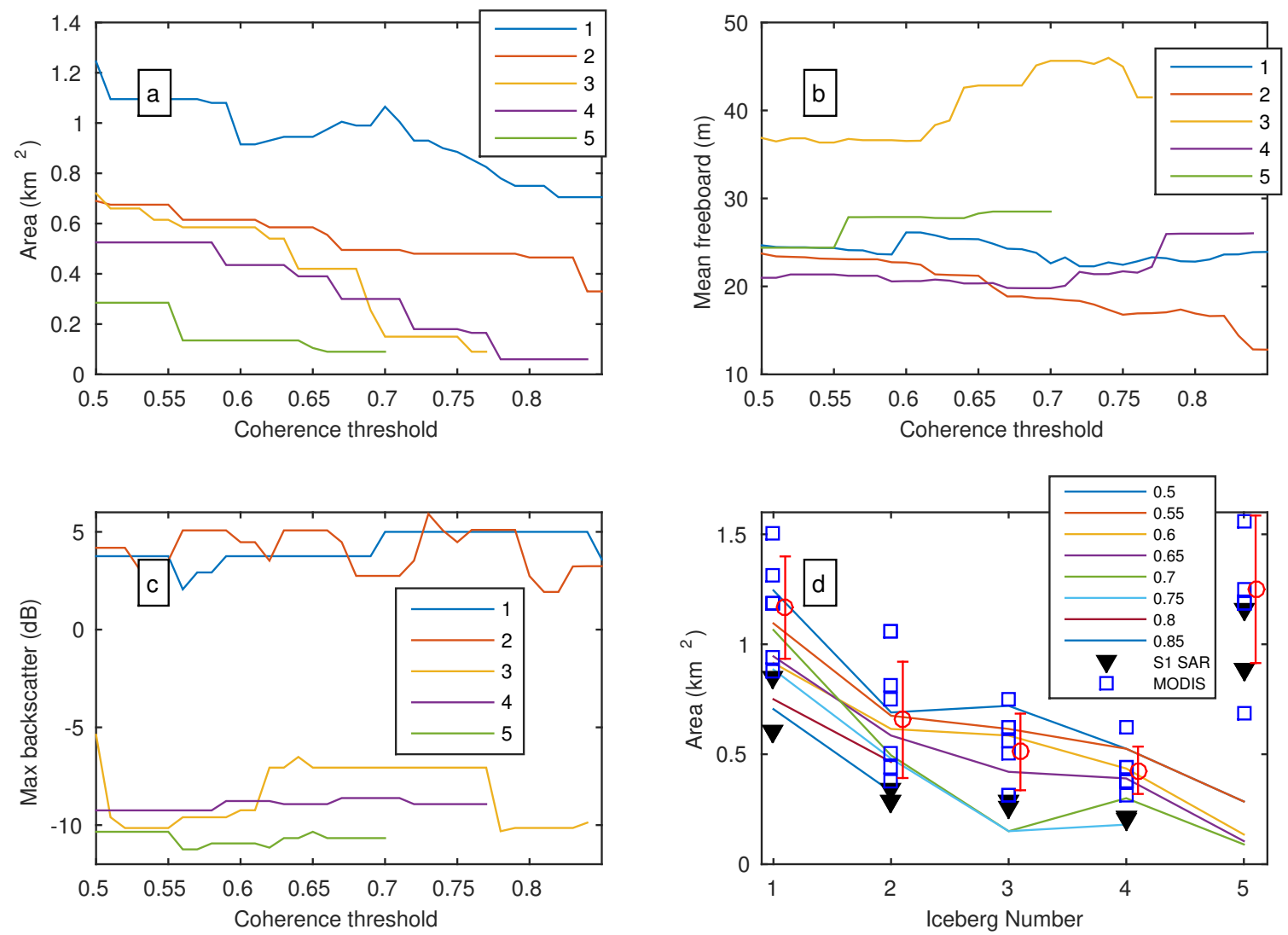

Figure B.2: (a) Area of the 5 icebergs of figure 7 as a function of the coherence threshold, (b) mean freeboard, (c) mean backscatter. (d) comparison of the SARin areas with Sentinel 1 (black triangle) and MODIS (blue square) images areas. The red error-bars represent the MODIS mean area and rms. 

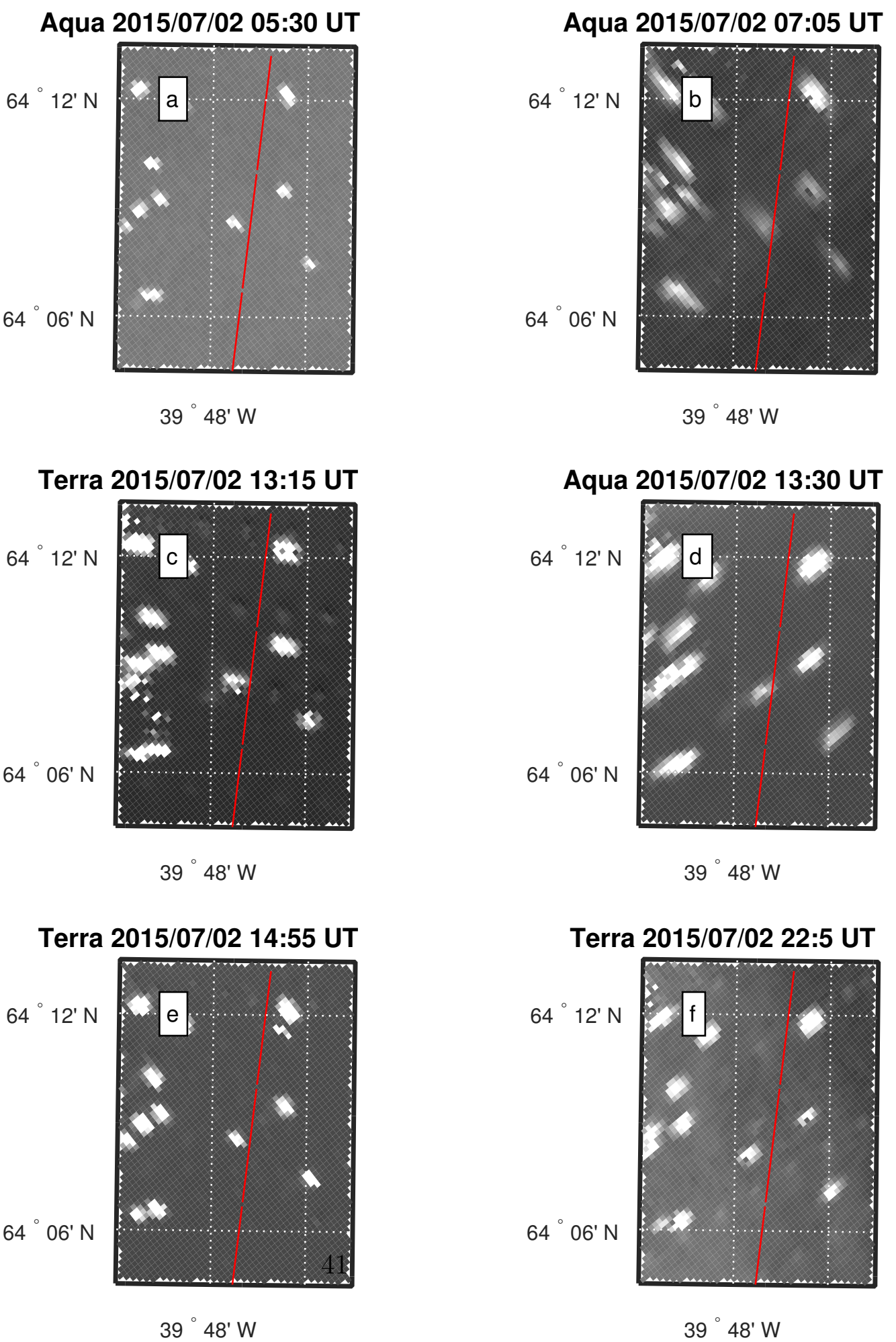

Figure B.3: MODIS images on July 2 2015. (a) Aqua 05:30 UT, (b) Aqua 07:05 UT, (c) Terra 13:15 UT, (d) Aqua 13:30 UT, (e) Terra 14:55 UT, (d) Terra 22:05 UT. The red 

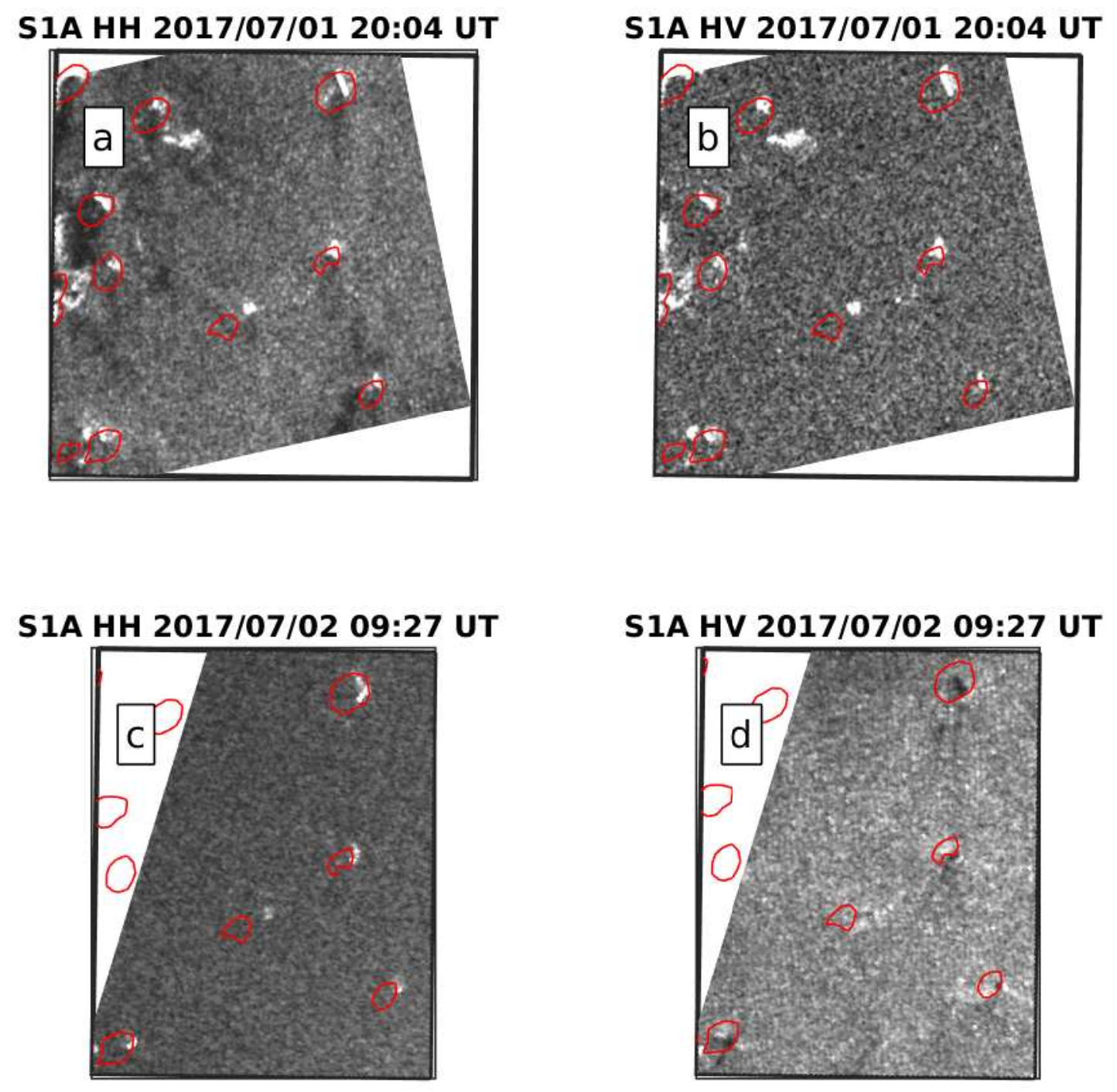

Figure B.4: Sentinel-1 wide Swath SAR images on July 1 and 2 2015. (a) HH and (b) HV polarization on July 1rst 20:04 UT, (c) HH and (d) HV polarization on July 2nd 09:27 UT. The red lines represents the icebergs detected in the MODIS images presented in figure B.2-c and translated to take into account the movement of the group of iceberg. 